\title{
The prescribing of psychotropic drugs in mental health services in Trinidad
}

\author{
Shelley Moore, ${ }^{1}$ Lazara K. Montane Jaime, ${ }^{1}$ Hari Maharajh, ${ }^{2}$ \\ Indar Ramtahal, ${ }^{2}$ Sandra Reid, ${ }^{1}$ Feroza Sircar Ramsewak, ${ }^{1}$ \\ and Mala Maharaj ${ }^{2}$
}

ABSTRACT Objective. To describe, analyze, and interpret patterns of psychotropic drug prescribing in new psychiatric patients attending psychiatric outpatient clinics in the Caribbean island of Trinidad.

Design and Methods. This was a cross-sectional study of psychotropic drug prescribing by psychiatrists for 132 new psychiatric outpatients who were seen at the outpatient clinics surveyed and who were entering the mental health system during the period of research, November 1998 through February 1999.

Results. A single patient could be prescribed more than one psychotropic drug. Antidepressant drugs were the class of psychotropic drugs most prescribed (79 of 132 patients, $59.8 \%$ ), followed by antipsychotic drugs (67 of 132 patients, 50.8\%). Tricyclic antidepressants (TCAs) were the antidepressants most prescribed (58 of the 79 patients), mainly amitriptyline (53 of the 58). Fluoxetine was the only selective serotonin reuptake inhibitor (SSRI) prescribed (21 of the 79 patients prescribed antidepressants). Of the 67 patients receiving antipsychotic drugs, phenothiazines accounted for 41 of those 67, including trifluoperazine (14 of the 41) and thioridazine (13 of the 41). The individual antipsychotic most prescribed was sulpiride (21 of the 67 patients). Anticholinergic drugs were prescribed to 20 of the 132 patients (15.1\%). Eighty-three of the patients were prescribed more than one drug concomitantly (either more than one psychotropic or a combination of psychotropic(s) and nonpsychotropic(s)). Prescription by ethnicity, age, and gender coincided with the morbidity rates encountered in these patients. The prescribing of SSRIs to persons of African or East Indian ethnicity was significantly lower than it was for persons of mixed heritage.

Conclusions. The prescription patterns of psychotropic drugs in Trinidad revealed the psychiatrists' preferences for traditional psychotropic drugs, the moderate use of anticholinergic drugs, and polypharmacy in some cases, with probable predisposition to adverse drug reactions. Given our results and based on the evaluation of individual patients, consideration should be given to a broader use of the newer antidepressants (SSRIs) and antipsychotics. Unless justified, polypharmacy should be avoided.

Key words Psychotropic drugs, drug therapy, drug utilization, mental disorders, Trinidad and Tobago.

1 The University of the West Indies, St. Augustine, Trinidad and Tobago. Send correspondence to: L.K. Montane Jaime, Pharmacology Unit, Faculty of Medical Sciences, The University of the West Indies, Trinidad and Tobago; Fax/Phone: (868) 663-8613; e-mail: lkjaime@yahoo.com

2 St. Ann's Mental Hospital, Port-of-Spain, Trinidad and Tobago.
The rapidly expanding field of psychopharmacology is challenging the traditional concepts of psychiatric treatments, and research is constantly seeking new and improved drugs to treat psychiatric disorders (1). In this way, psychiatrists are continuously exposed to newly introduced drugs that are claimed to be safer and more efficacious.

Appropriate pharmacotherapy is best achieved when the selection of a drug and its dosage regimen is based on patient-specific factors. This pro- 
cess must include taking complete current-drug and coexisting-disease histories in order to avoid possible drug-drug interactions and adverse effects. In addition, socioeconomic and demographic factors must be taken into consideration in order to ensure patient compliance and success of therapy. Besides rational considerations, the use of psychotropic drugs may also be determined by social, psychological, and cultural motives that can shape the therapeutic behavior of psychiatrists as well as the drug preferences of patients (2).

Before this study, no researchers had looked at these various psychopharmacology issues in the Caribbean island of Trinidad. Our objective was to describe, analyze, and interpret patterns of psychotropic drug prescribing in new psychiatric patients who were attending psychiatric outpatient clinics in Trinidad.

\section{MATERIALS AND METHODS}

We performed a cross-sectional survey of psychotropic drug-prescribing practices in new patients attending seven mental health outpatient clinics in Trinidad. Trinidad is the southernmost island of the Lesser Antilles. It is also the larger and more-populous of the two islands that make up the country of Trinidad and Tobago. The total population of the country is around 1.3 million, with some $96 \%$ of these persons living in Trinidad. Trinidad has a multiethnic society, mainly composed of people of African heritage $(39.6 \%)$ or of East Indian heritage $(40.3 \%)$. The remainder of the population is of White, Chinese, or mixed ancestry.

The seven outpatient clinics studied are part of the public health care system in Trinidad, which provides care at no cost to the patients. There are also private clinics with pharmacy facilities as well as private pharmacies, but these are not free of charge. All drugs are available in the private sector, but only those subsidized by the government are available in the public system.
All the data for our study were gathered by one of the researchers (S.M.), who was present during the interviews that the clinic psychiatrists conducted with all of the psychiatric patients attending one of the clinics for the first time. The data were collected from 10 November 1998 through 12 February 1999. Our study only included patients 15 years and over since patients under 15 years of age are not treated in the outpatient clinics but are instead referred to Child Guidance services.

The information collected included sociodemographic characteristics such as age, gender, ethnicity, educational level, and occupation. "Ethnicity" was determined on the basis of the patient having at least three of four grandparents from the same ethnic group. Toxic habits (such as smoking and illicit drug use) and coexisting diseases were also recorded. Drug information involved all drugs indicated for the psychiatric disorder as well as for any other medical reason. Immediately after the interview, the researcher reviewed the medical notes written by the psychiatrist in order to ensure that the information gathered was accurate. In addition, to check on information about any other drugs already being taken that the psychiatrist had not asked about, the researcher briefly interviewed the patient after the psychiatrist's interview and recorded any additional information provided.

All the patients were able to answer the questions that the psychiatrist asked. In addition, the family members of some patients were present and could verify the information that the patient had given. No patient refused to answer any of the questions.

The lists of psychotropic drugs available during the period of research were obtained from the head pharmacist of each of the pharmacies from the seven clinics studied. We only considered clinically significant drug interactions (3). The classification of drug-drug interactions was based on: a) potential harm to the patient, b) frequency and predictability of occurrence, and c) degree and quality of documentation. Highly clinically significant interactions refer to those of great potential harm to the patient, that occur frequently, and that are well documented. Moderately clinically significant interactions are those that are of moderate potential harm, that do not occur as frequently as the previous group, and that are not so completely documented (3).

\section{Statistical analysis}

We entered and analyzed our data using Epi Info version 6.02 computer software (Centers for Disease Control and Prevention, Atlanta, Georgia, United States of America). The chisquare test was used to find any differences in the use of the various psychotropic drugs by ethnicity, age group, or gender. Age was arranged in four groups: 15-19, 20-39, 40-59, and $60+$ years. The differences were considered statistically significant when $P<0.05$.

\section{RESULTS}

A total of 168 new psychiatric patients attended the seven psychiatric outpatient clinics during the period of research. Out of those 168, 36 patients were excluded, leaving 132 patients in our sample. Some of the 168 patients were eliminated due to age (i.e., less than 15 years old). Others were excluded for being recommended for hospitalization and treatment as inpatients, rather than as outpatients who would be prescribed medication at the initial psychiatric assessment.

\section{Patient characteristics}

Table 1 shows the distribution of the different sociodemographic characteristics of the 132 patients in the studied population. By ethnicity, the single largest group were persons of East Indian ancestry. The largest group by age were those from 20 to 39 years old. Women outnumbered men by a wide margin.

With respect to marital status, the studied population had an almost 
TABLE 1. Sociodemographic characteristics of 132 new psychiatric patients in the mental health services of Trinidad, 1998-1999

\begin{tabular}{lrr}
\hline Characteristic & No. & $\%$ \\
\hline Ethnic group & & \\
East Indian & 60 & 45.5 \\
African & 39 & 29.5 \\
Mixed & 33 & 25.0 \\
Age group (years) & & \\
15-19 & 13 & 9.8 \\
20-39 & 53 & 40.2 \\
40-59 & 39 & 29.5 \\
60+ & 27 & 20.5 \\
Gender & & \\
Male & 51 & 38.6 \\
Female & 81 & 61.4 \\
Marital status & & \\
Married & 48 & 36.4 \\
Single & 51 & 38.6 \\
Divorced & 3 & 2.3 \\
Widowed & 13 & 9.8 \\
Separated & 9 & 6.8 \\
Common-law & 8 & 6.1 \\
Educational level & & \\
No schooling & 8 & 6.1 \\
Primary & 70 & 53.0 \\
Secondary & 43 & 32.6 \\
Tertiary & 7 & 5.3 \\
Other & 4 & 3.0 \\
\hline
\end{tabular}

a "Other" = special schools (e.g., school for the physically challenged).

even distribution between patients who were married $(36.4 \%)$ and those who were single (38.6\%). Most of the patients $(73.5 \%)$ were unemployed. Most of the patients had completed primary or secondary education $(53.0 \%$ and $32.6 \%$, respectively).

\section{Psychiatric diagnoses}

All the clinic psychiatric consultants in the study said that to diagnose their patients they used the Diagnostic and Statistical Manual of Mental Disorders, Fourth Edition (DSM-IV), published by the American Psychiatric Association. Mood disorders represented $47.7 \%$ (71 of 149) of all diagnoses, with major depression being the most frequent, especially in patients of East Indian ancestry. (The overall number of psychiatric diagnoses, 149, was higher than the number of patients in the study because some of the 132 patients were given more than one diagnosis, that is, a major diagnosis and a coexisting condition.) Schizophrenia and other related disorders (29 of 149, or $19.5 \%$ ) were the next most frequent diagnoses, mainly in patients of African ancestry, while anxiety disorders represented $10.1 \%$ (15 of 149). Substancerelated disorders accounted for 3.4\% (5 of 149); these were mainly addictions to alcohol or illegal drugs. The category of "others" (29 diagnoses) included diagnoses with small numbers of patients that were therefore grouped for better statistical analysis.

\section{Coexisting diseases}

While some of the patients presented with no other medical illnesses, the overall number of coexisting disorders, 159 , was higher than the total number of patients in the study because some patients had more than one diagnosis of a coexisting disorder. Cardiovascular disorders (30 of 159 diagnoses, or $18.9 \%$ ) were the most prevalent coexisting illness encountered, with hypertension representing $60.0 \%$ (18 of 30) of this number. Endocrine disorders (17 of 159 , or $10.7 \%$ ) were the next most prevalent medical complaint, with diabetes mellitus accounting for 12 of the 17 and hypothyroidism accounting for the remaining 5 of the 17 . Other illnesses were grouped under the category of "others" and accounted for $25.2 \%$ (40 of 159) of the diagnoses of coexisting disorders.

\section{Psychotropic drug use}

A single patient could be prescribed more than one psychotropic drug. Antidepressant drugs were the class of psychotropic drugs most prescribed (79 of 132 patients, or $59.8 \%$ ), followed by antipsychotic drugs (67 of 132 patients, 50.8\%). Benzodiazepines were prescribed to $9.1 \%$ of the patients (12 of 132), while the anticholinergic drugs represented $15.2 \%$ (20 of 132).

Among the antidepressant drugs, tricyclic antidepressants (TCAs) were prescribed to 58 patients, and selective serotonin reuptake inhibitors (SSRIs) to 21 patients. Of the 58 TCA prescriptions, 53 of them were for amitriptyline, followed by imipramine (3 prescriptions) and amineptine and trimipramine (1 prescription each). The only SSRI prescribed was fluoxetine.

Of the antipsychotics prescribed (67 patients), phenothiazines accounted for 41 of the $67(61.2 \%)$. The main phenothiazines prescribed were trifluoperazine (14 of the 41 patients) and thioridazine (13 of the 41). These two were followed by chlorpromazine ( 6 of the 41), pipotiazine palmitate depot injection (5 of the 41), and fluphenazine decanoate depot injection (3 of the 41). Interestingly, sulpiride (21 of the 67 patients, or $31.3 \%$ ) was the individual antipsychotic most prescribed, and haloperidol was prescribed to only 3 of the 67 patients (4.5\%).

For the benzodiazepines, there appeared to be no single agent more prescribed than any other.

Benztropine was prescribed to 13 of the 132 patients $(9.8 \%)$ and trihexyphenidyl to 7 of the $132(5.3 \%)$.

\section{Concomitant drug use}

Out of the 132 patients, there were 127 for whom the data were complete enough to allow us to access concomitant drug use. Of those 127, 44 were using only one drug, that is, just a psychotropic drug. The other 83 patients were using two or more drugs, either more than one psychotropic or a combination of psychotropic(s) and nonpsychotropic(s). Of these 83 patients, 63 of them were using either two or three drugs concomitantly, 17 of them were using four or five drugs, and 3 of them were using six or more drugs.

Out of this group of patients using two or more drugs concomitantly, 51 of them were using nonpsychotropic drugs. Of these 51,41 of them were using drugs prescribed by another physician, that is, not the psychiatrist at the clinic. In addition, 15 of the 51 were self-medicating, according to their self-reporting.

In terms of the groups of nonpsychotropic drugs used concomitantly, 
TABLE 2. Use of psychotropic drugs, by ethnicity, among 132 new psychiatric patients in the mental health services of Trinidad, 1998--1999

\begin{tabular}{|c|c|c|c|c|c|c|c|}
\hline \multirow{2}{*}{$\begin{array}{l}\text { Psychotropic } \\
\text { drug }\end{array}$} & \multicolumn{2}{|c|}{$\begin{array}{l}\text { East Indian } \\
\quad(n=60)\end{array}$} & \multicolumn{2}{|c|}{$\begin{array}{l}\text { African } \\
(n=39)\end{array}$} & \multicolumn{2}{|c|}{$\begin{array}{c}\text { Mixed } \\
(n=33)\end{array}$} & \multirow[b]{2}{*}{$P$ value } \\
\hline & No. & $\%$ & No. & $\%$ & No. & $\%$ & \\
\hline Antidepressants & & & & & & & $0.005^{a}$ \\
\hline TCAs & 34 & 56.7 & 16 & 41.0 & 8 & 24.2 & \\
\hline SSRIs & 9 & 15.0 & 2 & 5.1 & 10 & 30.3 & \\
\hline Antipsychotics & & & & & & & 0.390 \\
\hline Phenothiazines & 11 & 18.3 & 15 & 38.4 & 15 & 45.5 & \\
\hline Others & 11 & 18.3 & 10 & 25.6 & 5 & 15.2 & \\
\hline Anxiolytics & & & & & & & $N A^{b}$ \\
\hline Benzodiazepines & 5 & 8.3 & 4 & 10.3 & 3 & 9.1 & \\
\hline Anticholinergics & & & & & & & 0.970 \\
\hline Trihexyphenidyl & 2 & 3.3 & 3 & 7.7 & 2 & 6.1 & \\
\hline Benztropine & 5 & 8.3 & 4 & 10.3 & 4 & 12.1 & \\
\hline
\end{tabular}

the most common were antihypertensives, followed by antidiabetics and nonsteroidal anti-inflammatory drugs.

\section{Psychotropic drug utilization and sociodemographic characteristics}

Ethnicity. Table 2 shows the patterns found in terms of the prescribing of psychotropic drugs by ethnicity. Only one difference was statistically significant; that was for the prescribing of antidepressants. Persons of African or East Indian descent were prescribed SSRIs less often than were persons of mixed ethnicity.
Age group. There were no statistically significant differences in the prescribing of psychotropic drugs by age group (Table 3). However, there was a trend of prescribing TCAs at a higher rate than SSRIs for those 40-59 and those 60 and older.

Gender. Female patients were prescribed antidepressants more than they were antipsychotics, while the reverse was true for males (Table 4). TCAs were prescribed much more frequently than were SSRIs, to both males and females. For males, the prescribing of phenothiazines was much greater than that of other antipsychotics, but for fe- males there was only a small difference. The rate of benzodiazepine prescribing for females was about twice the rate for males. Conversely, anticholinergic prescriptions were about twice as common for men as they were for women.

\section{Smoking}

Of the 132 patients, 99 of them $(75.0 \%)$ were nonsmokers, and 23 of the $132(17.4 \%)$ were reportedly smoking 24 or more cigarettes per day. Of these 23 heavy smokers, 14 of them were given antidepressant prescrip-

TABLE 3. Prescribing of psychotropic drugs by age (years) among 132 new psychiatric patients in the mental health services of Trinidad, 1998-1999

\begin{tabular}{|c|c|c|c|c|c|c|c|c|c|}
\hline \multirow[b]{2}{*}{ Psychotropic Drugs } & \multicolumn{2}{|c|}{$\begin{array}{c}15-19 \\
(n=13)\end{array}$} & \multicolumn{2}{|c|}{$\begin{array}{l}20-39 \\
(n=53\end{array}$} & \multicolumn{2}{|c|}{$\begin{array}{c}40-59 \\
(n=39)\end{array}$} & \multicolumn{2}{|c|}{$\begin{array}{c}60+ \\
(n=27)\end{array}$} & \multirow[b]{2}{*}{$P$ value } \\
\hline & No. & $\%$ & No. & $\%$ & No. & $\%$ & No. & $\%$ & \\
\hline TCAs & 2 & 15.4 & 20 & 37.7 & 23 & 59.0 & 13 & 48.1 & \\
\hline SSRIs & 2 & 15.4 & 11 & 20.8 & 6 & 15.4 & 2 & 7.4 & \\
\hline Antipsychotics & & & & & & & & & 0.206 \\
\hline Anxiolytics & & & & & & & & & a \\
\hline Benzodiazepines & 0 & 0.0 & 7 & 13.2 & 4 & 10.3 & 1 & 3.7 & \\
\hline Anticholinergics & & & & & & & & & $b$ \\
\hline Trihexyphenidyl & 1 & 7.7 & 5 & 9.4 & 1 & 2.6 & 0 & 0.0 & \\
\hline Benztropine & 3 & 23.1 & 5 & 9.4 & 4 & 10.3 & 1 & 3.7 & \\
\hline
\end{tabular}

a A $P$ value was not computed for anxiolytics since only one group (benzodiazepines) was used in the study.

${ }^{\mathrm{b}} \mathrm{A} P$ value was not calculated for the anticholinergics because one of the cell values was 0 . 
TABLE 4. Prescribing of psychotropic drugs by gender among 132 new psychiatric patients in the mental health services of Trinidad, 1998-1999

\begin{tabular}{|c|c|c|c|c|c|}
\hline \multirow[b]{2}{*}{ Psychotropic drugs } & \multicolumn{2}{|c|}{$\begin{array}{c}\text { Male } \\
(n=51)\end{array}$} & \multicolumn{2}{|c|}{$\begin{array}{l}\text { Female } \\
(n=81)\end{array}$} & \multirow[b]{2}{*}{$P$ value } \\
\hline & No. & $\%$ & No. & $\%$ & \\
\hline Antidepressants & & & & & 0.294 \\
\hline TCAs & 18 & 35.3 & 40 & 49.4 & \\
\hline SSRIS & 4 & 7.8 & 17 & 21.0 & \\
\hline Antipsychotics & & & & & 0.148 \\
\hline Phenothiazines & 23 & 45.1 & 18 & 22.2 & \\
\hline Others & 10 & 19.6 & 16 & 19.8 & \\
\hline Anxiolytics & & & & & a \\
\hline Benzodiazepines & 4 & 7.8 & 8 & 15.7 & \\
\hline Anticholinergics & & & & & 0.418 \\
\hline Trihexyphenidyl & 5 & 9.8 & 2 & 2.5 & \\
\hline Benztropine & 6 & 11.8 & 7 & 8.6 & \\
\hline
\end{tabular}

a A $P$ value was not computed for anxiolytics since only one group (benzodiazepines) was used in the study.

tions; 8 received TCAs and 6 received SSRIs.

Antipsychotic prescriptions were given to 13 of the 23 heavy smokers. In addition, benzodiazepine was prescribed to 5 of the 23 .

Anticholinergics were mostly prescribed to nonsmokers.

\section{Drug interactions}

We identified 20 potential drug-drug interactions among the 83 patients who were prescribed more than one drug concomitantly. Most of these potential interactions were of moderate clinical significance. Cases of psychotropic prescriptions for patients with coexisting diseases were found, which could predispose to adverse reactions. These patients require close monitoring or use of an alternative drug.

\section{DISCUSSION}

The study of psychotropic drug prescription in new patients is important since the initial treatment selected is of significance for therapeutic success and patient compliance. Therefore, treatment should be carefully chosen by weighing the relative risks and benefits of different therapeutic regimens on the basis of an evaluation of the condition of the patient and the need for patient-specific treatment.

Our study found that antidepressant drugs were the most-prescribed psychotropic drug, followed by antipsychotic drugs. This is in accordance with the fact that depression and schizophrenia had the highest reported morbidity rates among these patients. Patients of East Indian ancestry were prescribed significantly more antidepressants since depression was more frequently diagnosed in this ethnic group. Patients of African ancestry received more antipsychotics since they were more frequently diagnosed with schizophrenia. Females presenting to the clinics were diagnosed more frequently with depression and males with schizophrenia, which also explains why antidepressants rather than antipsychotics were prescribed more for females.

Psychiatrists in Trinidad are still prescribing TCAs over SSRIs for their patients. This may be due to three factors: 1) the erratic and inconsistent availability of SSRIs in some clinics (the medication does not always reach the public clinics on a timely basis), 2) the higher cost of SSRIs (but as these drugs are provided free of charge to the patients in the clinics, the limiting factor could be the cost of importing and distributing them), and 3) psychiatrists are more accustomed to or more comfortable with prescribing the traditional agents.

Both SSRIs and TCAs have been reported as having similar onset of action and therapeutic efficacy. The benefit with SSRIs seems to be the lower incidence of side effects (lack of sedative, anticholinergic, and hypotensive effects); the wider therapeutic index, making them safer in terms of possible overdose; and the once-daily dosing, which may improve patient compliance (4-6). The prescription of SSRIs was significantly lower than that of TCAs in patients of African ancestry as compared with persons of East Indian heritage. Some psychiatrists in the Caribbean believe that fluoxetine is less efficacious in patients of African heritage; this may explain the lower use of SSRIs in patients of this ethnic group in our sample.

Amitriptyline was the TCA most prescribed, although 6 of the 7 outpatient clinic pharmacies had imipramine available during the period of research. Fluoxetine was the only SSRI prescribed, as it is the only SSRI available in the clinics. There was a trend of prescribing TCAs more often to patients aged $40-59$ and $60+$. This occurs despite the recommendation of SSRIs for elderly people because of the increased potential for significant clinical problems with the anticholinergic side effects of TCAs $(7,8)$.

There is also a clear preference by psychiatrists in Trinidad for phenothiazines as compared to other types of typical antipsychotic drugs. Although all typical antipsychotics are equally effective, they differ in their propensity to induce side effects (9). Haloperidol produces less sedation, fewer anticholinergic effects, and fewer cardiovascular effects but at the cost of a higher incidence of extrapyramidal effects. Although no consensus is available, many feel that the side-effect profile of haloperidol is easier for the clinician to manage and is better tolerated by the patient. When analyzing individual drugs, we found that sulpiride was the individual antipsychotic drug most used. While the risk of extrapyramidal side effects is as great as with more-potent drugs, psy- 
chiatrists in Trinidad have commonly found that sulpiride is well tolerated. Antipsychotic depot injections are usually not recommended for patients at the first presentation. However, if the patient lacks insight into the illness and will clearly be noncompliant, it may be prescribed. This was done for one-fifth of the patients for whom antipsychotics were prescribed.

While the prescription of classes of antipsychotics was not significantly different among the ethnic groups, there was a trend to prescribe phenothiazines more frequently to patients of mixed ethnicity. Sulpiride and haloperidol were the individual drugs prescribed at a higher rate than any single phenothiazine in patients 20-39 years old.

Among the different medications available to treat acute extrapyramidal side effects, benztropine and trihexyphenidyl were used. Given the high rate of acute extrapyramidal side effects among patients receiving antipsychotic medications, especially the elderly, the short-term prophylactic use of anticholinergic drugs may be considered. The benefit of this approach has been demonstrated in several studies (9). The risk is that some patients may be treated unnecessarily. The data in our study show that the use of anticholinergic agents was reserved for only a small number of cases. The number of patients who presented to the clinics with anxiety disorders was small, hence the small number of prescriptions of benzodiazepines.

Comorbid psychiatric conditions or coexisting medical diseases are usually found in psychiatric patients, hence the need to use more than one drug. If more than one drug is chosen, it is recommended that the patient be closely monitored for adverse effects. We found that some patients in our study were prescribed combinations of drugs that could lead to drug-drug interactions, in some cases of moderate clinical significance but in others of highly clinical significance. Although moderately significant interactions are less of a threat than highly significant interactions, it does not mean that these moderate ones are to be ignored. Other research has found that interactions are likely to occur in some patients; therefore, the potential risk to the patient has to be assessed and appropriate action taken (3).

The use of polypsychopharmacy in our patients was not small. Antipsychotic and antidepressant users were more frequently subjected to polypsychopharmacy than were others. The most prevalent combinations were antipsychotic-antipsychotic and antidepressant-anxiolytic. It has been reported that two antipsychotics are no more effective than a single agent (10, 11). However, the incidence of side effects may increase, including extrapyramidal effects, and thus the possible additional need for anticholinergics to counteract these effects. Additionally, since this is the patient's first visit to the clinic, a trial with a single drug is recommended, and further evaluations would determine the need for any additional steps.

Combinations of antidepressants are sometimes used, although the benefit to be derived from polypharmacy has not been demonstrated in blinded studies and is likely to be outweighed by the increased risk of the combined side effects (12). One combination we found was fluoxetine and a TCA (five patients). It has been reported that fluoxetine may lead to a more rapid down-regulation of postsynaptic betaadrenergic receptors, thus possibly contributing to a faster onset of action of TCAs. However, fluoxetine impairs the hepatic oxidative metabolism of TCAs, which can result in an increase of $100 \%-300 \%$ in TCA plasma concentration as well as an increase in adverse effects, including seizures and delirium (12-15). Fluoxetine was also combined with benzodiazepines in two of the patients in our study. Fluoxetine may decrease the metabolism of benzodiazepines through competitive inhibition at the cytochrome P450 site, resulting in increased levels of benzodiazepines and an increase in their clinical effects (16). Fluoxetine has also been shown to increase the maximum concentration, the area under the curve, and the half-life of al- prazolam and to decrease the alprazolam elimination rate constant $(17,18)$.

The interaction between carbamazepine and fluoxetine (combined in one patient in our study) has been rated as "potentially hazardous," and combined administration of the drugs involved should be "avoided" or only undertaken with caution and appropriate monitoring $(19,20)$. The seizureconvulsive threshold is lowered by this combination, and also the plasma concentration of carbamazepine could be increased and resultant adverse effects could occur.

Three patients received TCAs while having concomitant treatment with propranolol. This beta-blocker decreases blood flow to the liver, so metabolism of TCAs may decrease, leading to accumulation of TCAs and possible toxicity. The mechanism is not totally understood (21). TCAs also reduce the effects of sublingual nitrates due to the predisposition to dryness of the mouth. This is of moderate clinical significance, and the addition of TCAs to the therapy of patients using nitrates should be carefully assessed and an alternative chosen if possible (22). We found this combination in four patients in our study.

The sedative and anticholinergic effects of either TCAs or phenothiazines may be prolonged and intensified with concomitant use due to the inhibition of the metabolism of both drugs (four patients in our study). The risk of seizures may be increased by lowering the seizure threshold, so drugs should be added or withdrawn with caution. Psychotic depressions respond well to a combination of TCAs and antipsychotic agents, but both agents should be initially administered at lower doses and increased as is clinically indicated. The risk of neuroleptic malignant syndrome may also be increased (23).

The mechanism of the interaction of selected phenothiazines and selected beta-blockers (combined in one patient in our study) is unknown; however, interference with metabolism is a likely possibility. There may be increased plasma levels, with resultant enhanced pharmacological response of each or both drugs as well as increased risk of 
toxicity. If both drugs are administered, the dosages should be adjusted as needed based on the patient's response. Serum chlorpromazine or thioridazine concentrations may decrease if beta-blocker therapy is discontinued. Similarly, plasma concentrations of the beta-blockers may decrease if chlorpromazine or thioridazine is discontinued $(24,25)$.

The concomitant drug use and toxic habits of the patients also have to be considered during the psychiatric interview and before choosing any drug. Many psychiatrists did not take a full drug history from the patients in our study, including that of toxic habits. Many psychotropics are metabolized by the liver, so smokers are at risk of having lower levels of the psychotropic agent by induction of hepatic microsomal enzymes by nicotine (26). As the ability to monitor patient plasma levels of drugs remains unavailable in Trin- idad, concomitant drug and cigarette use need to be considered.

\section{CONCLUSIONS}

This research study was the first that has been done with the aim of revealing the pattern of psychotropic drug prescribing in psychiatric outpatients in Trinidad. We found psychiatrists' preferences for traditional psychotropic drugs, including TCAs and phenothiazines; moderate use of anticholinergic drugs; polypharmacy in some cases, with probable predisposition to adverse drug reactions; and doctors sometimes not asking about concomitant drug use. Prescription by ethnicity, age, and gender coincided with the morbidity rate encountered in these patients.

Prescription of psychotropic drugs in new patients should be carefully done since the initial treatment selected is essential for therapeutic success and patient compliance. We encourage a broader use of the newer antidepressants (SSRIs) and antipsychotics, on the basis of an evaluation of the condition of the patient. Independent of which psychotropic drug is used, the presence of concomitant disorders that require pharmacological treatment should be considered in order to reduce adverse drug interactions. Unless justified, polypharmacy should be avoided.

We hope that this knowledge will be helpful in improving future prescribing practices in Trinidad.

Acknowledgement. Many thanks go to Dr. D. Simeon, a statistician with the Department of Community Health of The University of the West Indies.

\section{REFERENCES}

1. Pincus HA, Tanielian TL, Marcus SC, Olfson M, Zarin DA, Thompson J, et al. Prescribing trends in psychotropic medications: primary care, psychiatry and other medical specialties. JAMA 1998;279(7): 526-531.

2. Voirol P, Robert PA, Meister P, Oros L, Baumann P. Psychotropic drug prescription in a psychiatric university hospital. Psychopsychiatry 1999;32(1):29-37.

3. Zucchero FJ, Hogan MJ. Evaluations of drug interactions. St. Louis, Missouri, United States of America: PDS Publishing Co.; 1990.

4. Rickels K, Schweizer E. Clinical overview of serotonin reuptake inhibitors. J Clin Psychiatry 1990;51 Suppl B:9-12.

5. Dunbar GC, Cohn JB, Fabre LF, Feighner JP, Fieve RR, Mendels J, et al. A comparison of paroxetine, imipramine and placebo in depressed out-patients. Br J Psychiatry 1991;159: 394-398.

6. Montgomery SA. Sertraline in the prevention of depression [letter]. Br J Psychiatry 1992;161: 271-272.

7. Montgomery SA. Efficacy and safety of the selective serotonin reuptake inhibitors in treating depression in elderly patients. Int Clin Psychopharmacol 1998;13 Suppl 5:S49-54.

8. DasGupta K. Treatment of depression in elderly patients: recent advances. Arch Fam Med 1998;7(3):274-280.

9. American Psychiatry Association. Practice guideline for the treatment of patients with schizophrenia. Am J Psychiatry 1997;154:4.

10. Merlis S, Sheppard C, Collins L, Fiorentino D. Polypharmacy in psychiatry: patterns of dif- ferential treatment. Am J Psychiatry 1970; 126(11):1647-1651.

11. Rosholm JU, Hallas J, Gram LF. Concurrent use of more than one major psychotropic drug (polypsychopharmacy) in out-patients-a prescription database study. Br J Clin Pharmacol 1994;37(6):533-538.

12. Vaughan DA. Interaction of fluoxetine with tricyclic antidepressants. Am J Psychiatry 1988;145(11):1478.

13. Preskorn SH, Beber JH, Faul JC, Hirschfeld RM. Serious adverse effects of combining fluoxetine and tricyclic antidepressants. Am J Psychiatry 1990;147(4):532.

14. Westermeyer J. Fluoxetine-induced toxicity: extent and duration. J Clin Pharmacol 1991; 31(4):388-392.

15. Bergstrom RF, Peyton AL, Lemberger L. Quantification and mechanism of the fluoxetine and tricyclic antidepressant interaction. Clin Pharmacol Ther 1992;51(3):239-248.

16. Lemberger L, Rowe H, Bosomworth JC, Tenbarge JB, Bergstrom RF. The effect of fluoxetine on the pharmacokinetics and psychomotor responses of diazepam. Clin Pharmacol Ther 1988;43(4):412-419.

17. Lasher TA, Fleishaker JC, Steenwyk RC, Antal EJ. Pharmacokinetic-pharmacodynamic evaluation of the combined administration of alprazolam and fluoxetine. Psychopharmacology (Berl) 1991;104(3):323-327.

18. Greenblatt DJ, Preskorn SH, Cotreau MM, Horst WD, Harmatz JS. Fluoxetine impairs clearance of alprazolam but not of clonazepam. Clin Pharmacol Ther 1992;52(5):479-486.
19. Spina E, Avenoso A, Pollicino AM, Capurti AP, Fazio A, Pisani F. Carbamazepine coadministration with fluoxetine or fluvoxamine. Ther Drug Monit 1993;15(3):247-250.

20. Grimsley SR, Jann MW, Carter JG, D'Mello $\mathrm{AP}, \mathrm{D}$ 'Souza MJ. Increased carbamazepine plasma concentrations after fluoxetine coadministration. Clin Pharmacol Ther 1991;50(1): 10-15.

21. Stockley IH. Drug interactions. 3rd edition. London: Blackwell Scientific Publications; 1991.

22. British Medical Association and Royal Pharmaceutical Society of Great Britain. British National Formulary (BNF). London: BMA and RPSGB; 1998.

23. Davies DM. Textbook of adverse drug reactions. 4th edition. New York: Oxford University Press; 1991.

24. Miller FA, Rampling D. Adverse effects of combined propranolol and chlorpromazine therapy. Am J Psychiatry 1982;139(9):11981199.

25. Silver JM, Yudofsky SC, Kogan M, Katz BL. Elevation of thioridazine plasma levels by propranolol. Am J Psychiatry 1986;143(10): 1290-1292.

26. Kelly C, McCreadie RG. Smoking habits, current symptoms, and premorbid characteristics of schizophrenic patients in Nithsdale, Scotland. Am J Psychiatry 1999;156(11):1751-1757.

Manuscript received 16 August 2001. Revised version accepted for publication 7 June 2002. 
RESUMEN Objetivos. Describir, analizar e interpretar las características de la prescripción de psicotrópicos en pacientes nuevos que acudieron a las consultas externas de psiquiatría en la isla caribeña de Trinidad.

\section{Prescripción de psicotrópicos en los servicios de salud mental de Trinidad}

Métodos. Se realizó un estudio transversal de los psicotrópicos prescritos por psiquiatras a 132 nuevos pacientes psiquiátricos ambulatorios que acudieron a consultas externas por primera vez entre noviembre de 1998 y febrero de 1999.

Resultados. Algunos pacientes recibieron más de un psicotrópico. Los antidepresivos fueron los psicotrópicos recetados con mayor frecuencia (79 de los 132 pacientes, $59,8 \%)$, seguidos de los antipsicóticos (67/132; 50,8\%). Los antidepresivos prescritos con mayor frecuencia fueron los tricíclicos $(58 / 79 ; 73,4 \%)$, y en particular la amitriptilina $(53 / 58 ; 91,4 \%)$. La fluoxetina fue el único inhibidor selectivo de la recaptación de serotonina (ISRS) que se recetó $(21 / 79 ; 26,6 \%)$. De los 67 pacientes que recibieron antipsicóticos, a $41(61,2 \%)$ se les recetaron fenotiazinas, entre ellas la trifluoperazina $(14 / 41 ; 34,1 \%)$ y la tioridazina $(13 / 41 ; 31,7 \%)$. El antipsicótico prescrito con más frecuencia fue la sulpirida $(21 / 67 ; 31,3 \%)$. A 20 de los 132 pacientes $(15,1 \%)$ se les recetaron anticolinérgicos. A $83(62,9 \%)$ se les prescribió más de un fármaco simultáneamente: o bien más de un psicotrópico o una combinación de psicotrópicos y no psicotrópicos. La prescripción por etnia, edad y sexo coincidió con las tasas de morbilidad observadas en los diferentes grupos. La prescripción de ISRS a pacientes de origen africano o indio fue significativamente menos frecuente que a los de origen mixto.

Conclusiones. Estos resultados muestran una preferencia de los psiquiatras de Trinidad por los psicotrópicos tradicionales, un uso moderado de los anticolinérgicos $\mathrm{y}$, en algunos casos, el uso de la polifarmacia, que podría predisponer a la aparición de reacciones adversas graves. Teniendo en cuenta estos resultados y dependiendo de las circunstancias de cada paciente, se debería considerar un uso más amplio de los antidepresivos (ISRS) y antipsicóticos más recientes y evitar el uso de la polifarmacia,

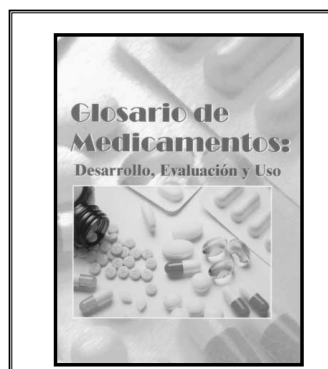

$1999 \cdot 312 \mathrm{pp}$.

ISBN 9275323054 Código: OT $118 \bullet$ Precio: US\$ 20.00/ US\$ 15.00 en América Latina y el Caribe

\section{Glosario de medicamentos: desarrollo, evaluación y uso}

Este libro no es solo una simple descripción de términos. Con el fin de facilitar al lector el uso de la literatura especializada en inglés, en él se ha incluido el equivalente, en ese idioma, de cada uno de los términos. El libro contiene, además, algunas advertencias en cuanto a las traducciones del inglés al español de términos relacionados con medicamentos, una hoja de instrucciones, una lista de abreviaturas, acrónimos, siglas, símbolos y sinónimos, así como un índice en inglés de los términos incluidos en el glosario.

Este glosario es de gran utilidad para los profesionales de la farmacología, de la medicina y de carreras afines que de una manera u otra se encuentran vinculados con organismos oficiales encargados de evaluar, registrar, seleccionar, y velar por el control de calidad de los medicamentos, así como de investigar su uso. 